\title{
Biotransformation and Cytotoxicity Evaluation of Kraft Lignin Degraded by Ligninolytic Serratia liquefaciens
}

\author{
Anil Kumar Singh',2, Pooja Yadav¹, Ram Naresh Bharagava ${ }^{3}$, \\ Ganesh Dattatraya Saratale ${ }^{4}$ and Abhay Raj ${ }^{1 *}$ \\ ${ }^{1}$ Environmental Microbiology Laboratory, Environmental Toxicology Group, CSIR-Indian Institute of Toxicology Research, \\ Lucknow, India, ${ }^{2}$ Academy of Scientific \& Innovative Research, Ghaziabad, India, ${ }^{3}$ Department of Microbiology, Babasaheb \\ Bhimrao Ambedkar University, Lucknow, India, ${ }^{4}$ Department of Food Science and Biotechnology, Dongguk University Seoul, \\ Seoul, South Korea
}

\section{OPEN ACCESS}

Edited by:

Shaohua Chen,

South China Agricultural University,

China

Reviewed by: Ang Li,

Harbin Institute of Technology, China Muhammad Bilal,

Shanghai Jiao Tong University, China

${ }^{*}$ Correspondence:

Abhay Raj

araj@iitr.res.in

Specialty section:

This article was submitted to Microbiotechnology, Ecotoxicology

and Bioremediation,

a section of the journa

Frontiers in Microbiology

Received: 25 May 2019 Accepted: 30 September 2019 Published: 21 November 2019

Citation:

Singh AK, Yadav $P$, Bharagava RN, Saratale GD and

Raj A (2019) Biotransformation and Cytotoxicity Evaluation of Kraft Lignin Degraded by Ligninolytic

Serratia liquefaciens.

Front. Microbiol. 10:2364. doi: 10.3389/fmicb.2019.02364
Various chemical compounds emerged including kraft lignin $(\mathrm{KL})$ during the processes of papermaking. These chemical compounds in effluent of the paper industry have hazardous environmental impacts. $\mathrm{KL}$ is liable for causing pollution of aquatic and water bodies; hence, it must be minimized in order to maintain a healthy and sustainable environment. In the present study, $\mathrm{KL}$ degradation was performed with ligninolytic bacterium Serratia liquefaciens and we confirmed biotransformation of $\mathrm{KL}$ to various less polluted or harmless compounds. $\mathrm{KL}$ being degraded as $1000 \mathrm{mg} / \mathrm{L}^{-1}$ concentration with incubating $30^{\circ} \mathrm{C}$ for 72,168 , and $240 \mathrm{~h}$, shaking at $120 \mathrm{rpm}$ under laboratory conditions. We found $65 \%$ maximum degradation of $\mathrm{KL}$ and $62 \%$ decolorization by the treatment with $S$. liquefaciens for $240 \mathrm{~h}$ (10 days). After being the treatment of $\mathrm{KL}$, clear changes were observed in its morphology (using scanning electron microscopy and stereo microscopy), hydrodynamic size (using dynamic light scattering), and the functional groups [using Attenuated Total Reflectance Fourier Transform Infrared Spectroscopy (ATR-FTIR)]. Biotransformation of KL monitored by Gas Chromatography-Mass Spectrometry (GC-MS) revealed formation of various metabolites. In addition to degradation of $\mathrm{KL}$, detoxification (involving biotransformation into various metabolites) was assessed using cytotoxicity assays 3-(4,5-dimethylthiazol2-yl)-2,5-diphenyltetrazolium bromide [MTT and calcein-acetoxymethyl (AM) assays] using a human kidney cell line (NRK-52E), which indicated improved cell survival rates (74\% for the bacteria-treated $\mathrm{KL}$ solution treated for $240 \mathrm{~h}$ ) compared to the control (27\%). Thus, the present study suggests that bacteria S. liquefaciens might be useful in reducing the pollution of $\mathrm{KL}$ by transforming it into various metabolites along with cytotoxicity reduction for environmental protection.

Keywords: kraft lignin, Serratia liquefaciens, biodegradation, biotransformation, cytotoxicity

\section{INTRODUCTION}

Paper manufacturing industries are one of the world's most polluting industries, emit, and expels highly toxic compound into the environment (Ince et al., 2011). In the pulp and paper industry's effluents, significant quantities of toxic chemicals have reported. These toxic chemicals in effluent generated during the different paper manufacturing process including kraft pulping, 
bleaching, delignification, etc. may be responsible for various serious environmental concerns. The high concentration of various chemical like sodium hydroxide, sodium sulfide, sodium carbonate, bisulfides along with chlorine elements (chlorine dioxide), hydrochloric acid are the chief ingredients of wastewater of paper industries (Suresh and Hung, 2004). Apart from enormous quantities of different harmful chemicals, lignin and various forms of lignin-derived compounds are responsible for the dark color of wastewater and contribute a high level of aquatic pollution when drained into it (Nath, 2016).

Kraft lignin (KL) is a major component of paper industries, which released through effluent during the delignification process. Many researchers have reported that KL is a key component of wastewater, causing color appearance and toxicity (Shi et al., 2013; Verma and Ekka, 2018). Similar to natural lignin, because the complicated three-dimensional structure of KL, a range of ether and carbon-carbon bond is extremely recalcitrant to chemical and biotransformation/biological degradation. KL colors even at a small level in water are noticeable $\left(25 \mathrm{mg} \mathrm{L}^{-1}\right)$, whereas paper industry effluent typically contains $>200$ $600 \mathrm{mg} \mathrm{L}^{-1} \mathrm{KL}$ (Singh, 2012; Raj et al., 2014; Haq et al., 2016). $\mathrm{KL}$ blocks the photosynthesis in the aquatic ecosystem and reduces the oxygen level, which often leads to toxicity in the aquatic ecosystem (Sponza, 2003; Latorre et al., 2007). Hence, the degradation of KL provides the biotransformation of KL in paper industry effluent during the degradation or treatment process.

Over the years, several lab-scale KL removal methods have been developed using physical and biological methods. Processes based on physical methods (sedimentation, coagulation, oxidation, etc.) and chemical techniques (adsorption, microfiltration, etc.) are effective but costly for large-scale application (Kamali and Khodaparast, 2015). Biological treatment fungal, bacterial, algae, and plant systems methods seem to be accessible to evaluated for the degradation or biotransformation of contaminants in paper industry effluent, including KL. More recently, biotransformation involving specific bacteria and fungi has been receiving more attention. During the last decade, several bacteria and fungi with the ability to degrade or biotransform various types of lignin have been isolated. The abilities of microorganisms to degrade lignin are due to their ligninolytic enzymatic systems, which include the following "ligninolytic": lignin peroxidases (LiPs), laccases (LACs), and manganese peroxidases (MnPs) (Chandra and Chowdhary, 2015; Chowdhary et al., 2018). These enzymes were initially reported in fungi and subsequently in bacteria (Saratale et al., 2009; Bugg et al., 2011; Harms et al., 2011). It has been reported that the bacterial ligninolytic system is more effective than the fungal system in terms of degradation and biotransformation of various forms of lignin into various metabolites (El Hanafy et al., 2008). The excellent enzyme production capabilities of bacteria have led to the huge demand for bacterial isolation that produces potential ligninolytic enzymes for degradation of paper mill pollutants by transforming into less toxic compounds. Recently reported, potential ligninolytic bacteria like; Bacillus, Arthrobacter, Nocardia, Pseudomonas, Streptomyces, etc. by various investigators has shown their paper mill pollutants degradation potential
(Chandra et al., 2007; Tian et al., 2016). Despite the key role-playing, ligninolytic bacteria have been focused on their enzymatic activity that's positively correlated with lignin mineralization and degradation (David Boyle et al., 1992).

The bacterial ligninolytic enzyme system is considered more stable in term of catalysis mechanism in a harsh environment than the fungi system; bacteria can usually accept a wider variety of habitats and grow more quickly than fungi (Harms et al., 2011). Furthermore, as contrasted to ligninolytic fungal enzymes, bacterial ligninolytic enzymes may be highly active in high temperatures and much stable, in high $\mathrm{pH}$ values, and concentrations of strong chloride and other organic chemicals (Sharma et al., 2007; Bugg et al., 2011; Dwivedi et al., 2011). LiP is an oxidoreductase enzyme, extracted and purified from fungi, which further employs for remediation of toxic compounds and colored removal from paper mill effluents (Mehboob et al., 2011). Apart from fungi, bacterial LiP has great potential as a ligninolytic enzyme due to huge biochemical versatility and adaptability to the environment of bacteria. Recently, we reported a LiP producing bacterium Serratia liquefaciens, isolated from effluent contaminated soil by lignin enrichment method, was able to degrade and detoxify pulp and paper mill effluent with significant reduction of lignin, 58\% (Haq et al., 2016). Since this isolate degraded significant amount of lignin, but its biodegradation process need to explore for greater understanding.

The present work was to assess the KL degradation ability of S. liquefaciens and characterization of its biodegradation process along with toxicological evaluation of the sample after bacterial treatment. This study has demonstrated KL biodegradation/biotransformation ability of this isolate, and has shown cytotoxicity reduction on human kidney cell lines. We found significant degradation, color removal, as well as cytotoxicity minimizing potential after employing S. liquefaciens.

\section{MATERIALS AND METHODS}

\section{Bacterial Inoculum Preparation}

The ligninolytic S. liquefaciens strain was isolated from the effluent of the paper mill (Haq et al., 2016). The isolate kept and maintained at $-20^{\circ} \mathrm{C}$ for long-term usage. It was used to inoculate mineral salt medium (MSM) agar plates $(\mathrm{pH} 7.6)$ containing the following media composition $\left(\mathrm{g} \mathrm{L}^{-1}\right): \mathrm{Na}_{2} \mathrm{HPO}_{4}$, 2.4; $\mathrm{K}_{2} \mathrm{HPO}_{4}, 2.0 ; \mathrm{NH}_{4} \mathrm{NO}_{3}, 0.1 ; \mathrm{MgSO}_{4}, 0.01 ; \mathrm{CaCl}_{2}, 0.01 ; \mathrm{KL}$ (Cat. No. 471003; Sigma-Aldrich, St. Louis, MO, United States), 1.0; D-glucose, 10.0; peptone, 5.0; and agar powder, 15.0. After $120 \mathrm{~h}$ of growth at $30^{\circ} \mathrm{C}$, the bacterial colonies were used to inoculate $50 \mathrm{~mL}$ MSM broth by incubated for $24 \mathrm{~h}$ in flasks in an incubator shaker at $30^{\circ} \mathrm{C}$. This freshly prepared bacterial culture was used to conduct the concerned experiments.

\section{KL Degradation Assay}

Kraft lignin biodegradation assay was conducted using KL (molecular weight, $\sim 10,000 \mathrm{Da}$ ), which was purchased from Sigma-Aldrich (Cat. No. 471003, St. Louis, MO, United States). It has low sulfonate content (4\%) and water-soluble. The $\mathrm{KL}$ degradation assay was performed in a flask $(1000 \mathrm{~mL})$ 
containing $500 \mathrm{~mL} \mathrm{MSM}$ and $\mathrm{KL}\left(1000 \mathrm{mg} \mathrm{L}^{-1}\right.$, measured COD $4030 \mathrm{mg} / \mathrm{L}$ ) adjusts $\mathrm{pH}$ at 7.6. $\mathrm{MSM}+\mathrm{KL}$-containing flask was inoculated with $1 \%(\mathrm{v} / \mathrm{v})$ fresh bacterial culture suspension followed by incubated at $30 \pm 0.5^{\circ} \mathrm{C}$ on an orbital shaker (Kuhner shaker) at $120 \mathrm{rpm}$. The samples were harvested at $0 \mathrm{~h}$ (before inoculation) and 72, 168, and $240 \mathrm{~h}$ after inoculation. The $<24$ h sample was used as the control or untreated. These conditions were used as the standard conditions for all $\mathrm{KL}$ degradation/biotransformation experiments (Ravi et al., 2019).

The harvested samples were assessed for bacterial growth, LiP activity, color, and lignin content. Optical density measurement was used to determine bacterial growth (OD) at $600 \mathrm{~nm}$ of the culture broth using a double-beam (UV) visible spectrophotometer (Shimadzu, Japan), with a non-inoculated medium as the blank control. LiP activity was measured by centrifugation of $2 \mathrm{ml}$ MSM broth culture, and centrifuged at $10,000 \mathrm{rpm}$ at $4^{\circ} \mathrm{C}$ for $10 \mathrm{~min}$. Supernatants were assessed based on the $\mathrm{OD}$ at $310 \mathrm{~nm}$ following $\mathrm{H}_{2} \mathrm{O}_{2}$-consistent veratryl alcoholdependent oxidation to veratraldehyde (Tien and Kirk, 1988). The activity of the enzyme was measured as IU/mL. The quantity of enzyme required to oxidize a micromole veratryl alcohol per milliliter per minute was recognized as a unit of LiP activity. The color intensity of the culture supernatants was assessed based on the OD at $465 \mathrm{~nm}$ using the Canadian Pulp and Paper Association (CPPA) (1974) method, after the $\mathrm{pH}$ of the supernatant has been set to 7.6. The estimation of lignin content was conducted using the Pearl and Benson (1940) method. Triplicate experiments were conducted and the values reported as mean $\pm S D(n=3)$.

\section{Characterization of KL Degradation}

The KL degradation assay conducted under standard conditions as described above. KL was extracted from the culture medium using the acid precipitation method (Chen et al., 2012; Lu et al., 2017). The dried KL powder used to characterize using scanning electron microscopy (SEM) and stereo microscopy.

\section{Scanning Electron Microscope and Stereomicroscope Analysis}

Structural and surface changes during the KL degradation assay induced by $S$. liquefaciens have evaluated at various time intervals by SEM and stereomicroscope analysis. KL powder samples were used Mini Sputter Coater to coat with gold (Model SC7620, Quorum, Technologies, United Kingdom) and followed by examined using SEM (Quanta 450 FEG, FEI, Netherlands) and energy dispersive X-ray (EDX) spectroscopy analysis. The morphology of the KL powder was also observed using a stereomicroscope (KH-7700, HIRO, Japan).

\section{Dynamic Light Scattering Measurements}

A dynamic light scattering (DLS) technique was used to quantifying diameter hydrodynamic $\left(D_{\mathrm{H}}\right)$ of the KL particles. The KL samples were diluted as 1/10 in MiliQ water. Followed by mean $D_{\mathrm{H}}$ in the $\mathrm{KL}$ samples were analyzed using a Zetasizer Nano-ZSP system (Malvern Instruments Ltd., Malvern, United Kingdom).

\section{Attenuated Total Reflectance-Fourier Transform Infrared Spectroscopy Analysis}

The Attenuated Total Reflectance (ATR)-Fourier Transform Infrared (FTIR) spectra of the KL powder samples (control and bacteria-treated) were recorded using a single-beam ATRFTIR spectrometer (Nicolet ${ }^{\mathrm{TM}}$ iS $^{\mathrm{TM}}$, Thermo Fisher Scientific, United States). ATR-FTIR equipment has configured for 16 scans in the range of $4000-500 \mathrm{~cm}^{-1}$ and a resolution of $4 \mathrm{~cm}^{-1}$.

\section{Gas Chromatography-Mass Spectrometry Analysis for Metabolite Identification}

Treated KL samples with SL and control sample prepared with cell-free culture supernatants in $50 \mathrm{~mL}$ quantities. Samples were extracted and derived using ethyl acetate and N,O-bis (trimethylsilyl) trifluoroacetamide with trimethylsilyl chloride (BSTFA + TMCS), respectively. A Gas ChromatographyMass Spectrometry (GC-MS) spectrometer used sample by injecting the silylated samples $(1 \mu \mathrm{l})$ (Ultra TSQ Quantum XLS Mass Spectrometer, Thermo Fisher Scientific, United States) according to the standard procedure (He and Aga, 2019). By comparing detected mass spectra to the compounds library of National Institute of Standards and Technology (NIST) (available with the spectrometer) identified as compound or metabolites present in samples.

\section{Cytotoxicity Evaluation}

Samples were determined to be cytotoxic by the used of 3-(4,5dimethylthiazol-2-yl)-2,5-diphenyltetrazolium bromide (MTT) and calcein-acetoxymethyl (AM) assays, described as standard procedures by Singh et al. (2015). When this kidney cell line (NRK-52E) was used for both assays. The cells kept in Dulbecco's modified Eagle's medium (DMEM) supplemented with 10\% heat-inactivated fetal bovine serum (FBS) and $1 \times$ antibacterialantimycotic (ABAM) solution in a $5 \% \mathrm{CO}_{2}$ atmosphere at $37^{\circ} \mathrm{C}$. The concerned cell line was used after they reached the confluence of 75-80\%. Quickly, $2 \times 10^{5}$ cells were grown on 96well plates, and maintained for $24 \mathrm{~h}$ in a $\mathrm{CO}_{2}$ incubator. The treatments involved incubation for $24 \mathrm{~h}$ at $37^{\circ} \mathrm{C}$ with $50 \mu \mathrm{l}$ of the untreated and bacteria-treated $(72,168$, and 240 h) KL samples and $200 \mu \mathrm{l}$ of the above-mentioned medium.

For the MTT assay of cytotoxicity, after 24-h KL treatment, MTT (GIBCO-Life Technologies, United States) added $\mathrm{L}^{-1}$ to each 96-well plates well with a final concentration of $0.5 \mathrm{mg}$. Further incubation at $37^{\circ} \mathrm{C}$ was performed for $2-3 \mathrm{~h}$. The medium was removed, and dimethyl sulfoxide (DMSO) formed the formazan crystals. The density of formazan crystals corresponds immediately to the sum of viable cells. The OD was measured at $570 \mathrm{~nm}$ with a Spectra Max MS Multimode Microplate Reader (Molecular Devices, United States).

For the AM assay of cytotoxicity, after 24-h KL treatment at $37^{\circ} \mathrm{C}$, the medium of culture was removed and cells washed with $1 \times$ phosphate-buffered saline (PBS), and then the diluted calcein-AM $(200 \mathrm{~mL})$ was added at the final of a $2 \mathrm{mM}$. After incubation at $37^{\circ} \mathrm{C}$ for $30 \mathrm{~min}$, cells were visualized and 
quantified under a fluorescent microscope at $10 \times$ magnification (Nikon Instruments Inc., United States) with an excitement rate of $488 \mathrm{~nm}$ and emission filters with $520 \mathrm{~nm}$. The statistical analysis was performed using the statistical program GraphPad Prism (San Diego, CA, United States) (Swift, 1997). The results are reported as mean $\pm S D(n=3)$.

\section{RESULTS AND DISCUSSION}

\section{KL Powder Characterization}

The surface morphology of the KL powder (obtained from Sigma-Aldrich, St. Louis, MO, United States) was characterized by SEM and EDX analysis. The morphological observations might be by the KL extraction method from black liquor (Fierro et al., 2006; Pua et al., 2011). The SEM images of the KL particles show rounded spherical shapes with smooth surfaces as depicted in Figure 1A. The EDX spectroscopy elemental analysis revealed that the KL powder had a low sulfur content (4.22\%) as shown in Figure 1B.

\section{KL Biodegradation Characterized by Spectrophotometric Analysis}

Kraft lignin degradation conducted and confirmed by LiPproducing S. liquefaciens, previously this strain has shown lignin degradation and color removal of paper mill effluents (Haq et al., 2016). The KL degradation and decolorization experiments performed for quantifying the degradation rate of $\mathrm{KL}$ and color removal, and examined in specific time intervals $(0,72,168$, and $240 \mathrm{~h}$ ) in MSM broth ( $\mathrm{pH} 7.6$ ) containing $1000 \mathrm{mg} \mathrm{L}^{-1} \mathrm{KL}$. The KL degradation was spectrophotometrically characterized at different time periods. The results with respect to bacterial growth, LiP activity, KL decolorization, and $\mathrm{KL}$ degradation indicated that growth and LiP activity $(23 \mathrm{IU} / \mathrm{ml})$ peaked at $168 \mathrm{~h}$ and then declined, whereas the maximum KL degradation as $65 \%$ and $62 \%$ decolorization were observed in $240 \mathrm{~h}$ (Figures 2A,B). The COD reduction during bacterial treatment was also measured and it was recorded that initial COD of $4030 \mathrm{mg} / \mathrm{l}$ was decreased to $1289 \mathrm{mg} / \mathrm{l}(68 \%)$ after $240 \mathrm{~h}$ of treatment (data not shown). The above results are quite improved in contrast to a recent study on $\mathrm{KL}$ decolorization and degradation induced by Pandoraea sp. ISTKB reported $41 \%$ degradation and 36\% decolorization after $48 \mathrm{~h}$ (Kumar et al., 2015). The KL degradation rate $65 \%$ of S. liquefaciens is quite higher than reported for Bacillus sp. ITRC S8 (37\%), A. aneurinilyticus ITRC S7 (33\%), and Paenibacillus sp. ITRC S6 (30\%) (Chandra et al., 2007). These findings indicate that bacteria are able to grow and produce improved LiP enzyme to induce KL degradation and its biotransformation.

Furthermore, it was observed that the KL content of MSM broth decreased during the initial hours of incubation despite the rapid bacterial growth. This lower decolorization in the initial phase (despite fast bacterial growth) might be due to the use of simple carbon (glucose) and peptone sources available from MSM growth media were only compulsory to use KL as a cosubstrate after the depletion of these sources. An earlier study on the degradation and decolorization of $\mathrm{KL}\left(500 \mathrm{mg} \mathrm{L}^{-1}\right)$ reported 30-40 and 40-65\% degradation due to Paenibacillus and Bacillus, respectively, with requirements for additional carbon and nitrogen sources (Chandra et al., 2007). The findings of this research are also consistent with studies by Ahmad et al. (2010) and Sainsbury et al. (2013).

\section{KL Surface Characterization After Treatment by Serratia liquefaciens}

The KL structural transformation process was studied by SEM analysis at different times. The magnification and scaling were kept similar in all SEM images. The SEM image of the KL isolated from the control (untreated) solution revealed that the rounded shapes of the KL particles became flat, with smooth surfaces, after dissolving in assay medium (MSM broth + bacteria) as shown in Figure 3A. The SEM images of the bacteria-degraded KL showed that the smooth surfaces eroded, which increased with incubation time shown in Figures 3B-D. This change was due to bacterial degradation, and the degradation was maximum observed after $240 \mathrm{~h}$ of incubation. Thus, the SEM images indicate significant degradation/transformation of KL structurally by $S$. liquefaciens. There has been a comparable finding reported by researchers who reported substantial degradation/biotransformation of KL by Pandoraea sp. ISTKB (Kumar et al., 2015). In a recent study it is found that $S$. liquefaciens-biotransformed alkali lignin exhibited less phototoxicity and cytotoxicity than untreated alkali lignin (Rybczyńska-Tkaczyk and Korniłłowicz-Kowalska, 2017).

Morphological changes of KL during the degradation process were also evaluated by stereo microscopy shown in Figure 4, which revealed the dark color of the untreated KL. However, with degradation, the dark color was gradually reduced due to the erosion of the KL surface. This indicates that lignin degradation occurs throughout constantly degradation process.

\section{KL Characterization by DLS}

Dynamic light scattering experiments to assess the $D_{\mathrm{H}}$ of the untreated and bacteria-treated KL samples were also performed. The peak for the untreated KL sample corresponds to a $D_{\mathrm{H}}$ of $334.8 \mathrm{~nm}$. After treatment by bacteria, the overall size of KL particles was decreased compared to the control of KL particles. After 72,168 , and $240 \mathrm{~h}$, the KL size decreased by $10.2,12.6$, and $18.0 \%$, with corresponding $D_{\mathrm{H}}$ values of $300.4,292.8$, and $275.1 \mathrm{~nm}$, respectively, data shown in Table 1. The results suggested that after bacterial treatment, the larger KL particles became smaller compared to the control of KL particles. Similar results were recently described after Lignosulfonate degradation induced by Sphingobacterium sp. HY-H and KL degradation induced by Penicillium chrysogenum var. halophenolicum (Wang et al., 2013; Remedios et al., 2016).

\section{KL Characterization by ATR-FTIR}

The ATR-FTIR analysis was carried out in order to analyze the changes in functional group composition of KL after bacterial treatment, on the untreated and bacterial-treated sample. There were differences between the ATR-FTIR spectra for the control sample and the bacterial-treated samples at various time points $(72,168$, and 240 h), as shown in Figure 5. 


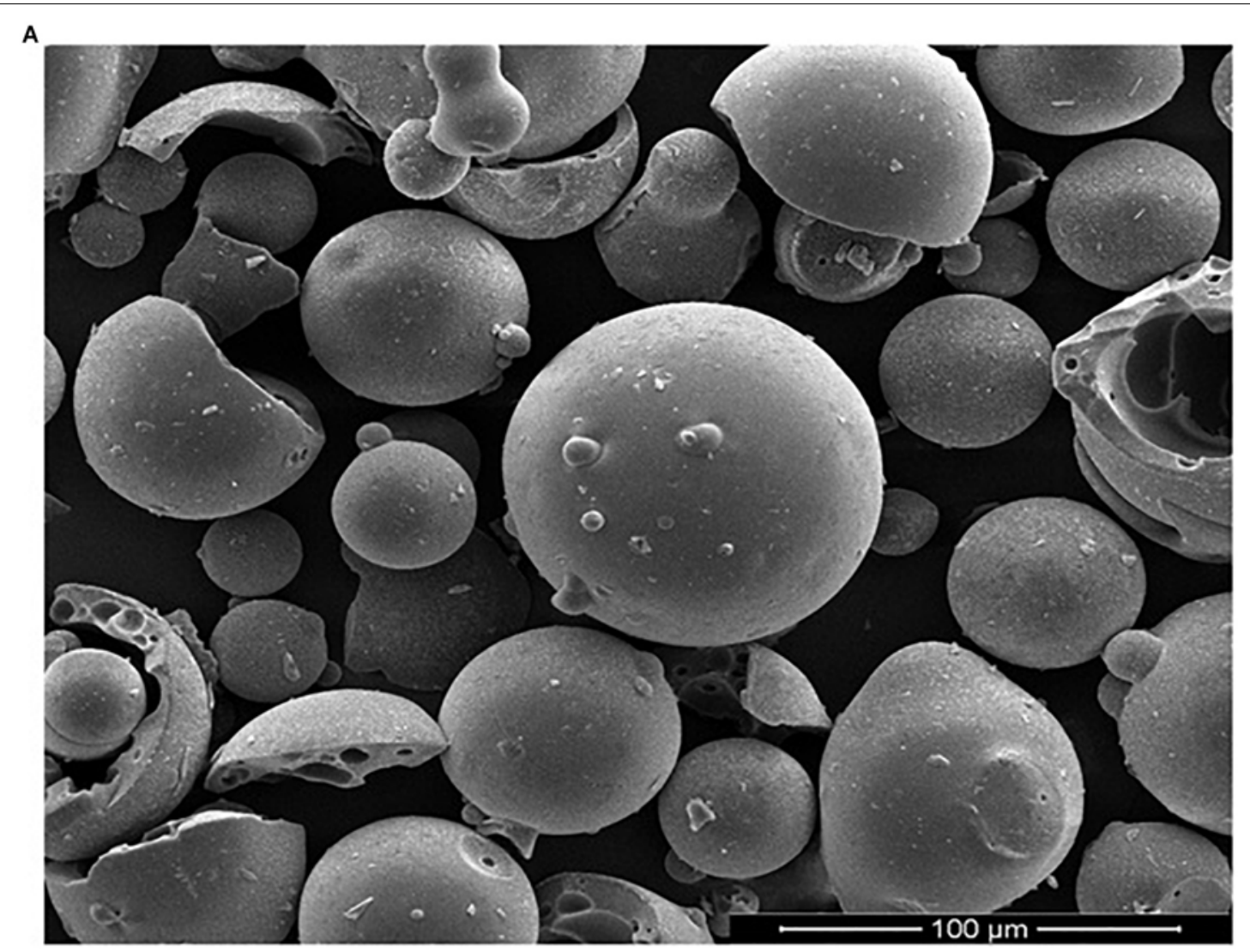

B

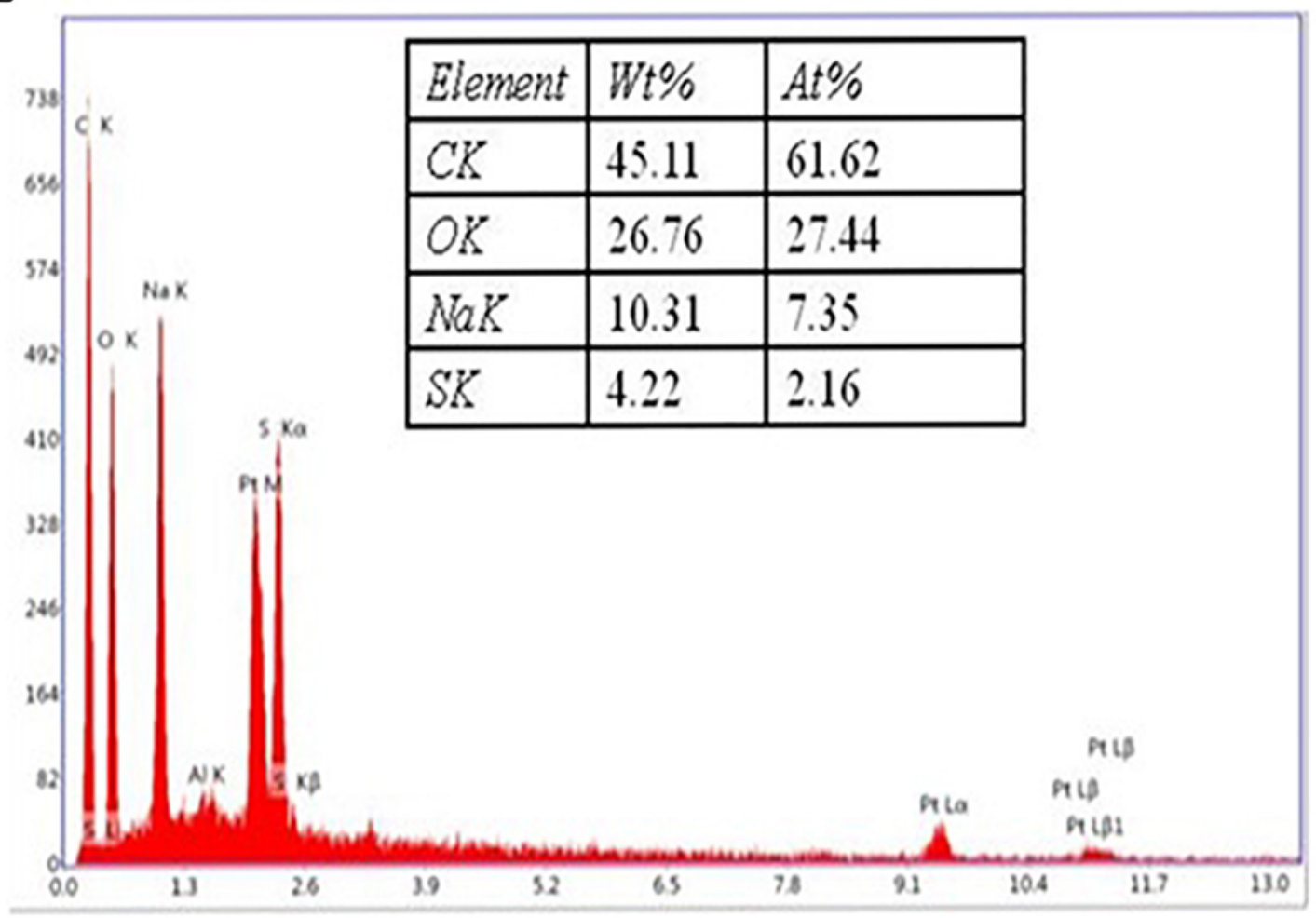

FIGURE 1 | (A) The SEM images of the kraft lignin particles, showing rounded spherical shapes with smooth surfaces. (B) EDX spectra of KL powder. 


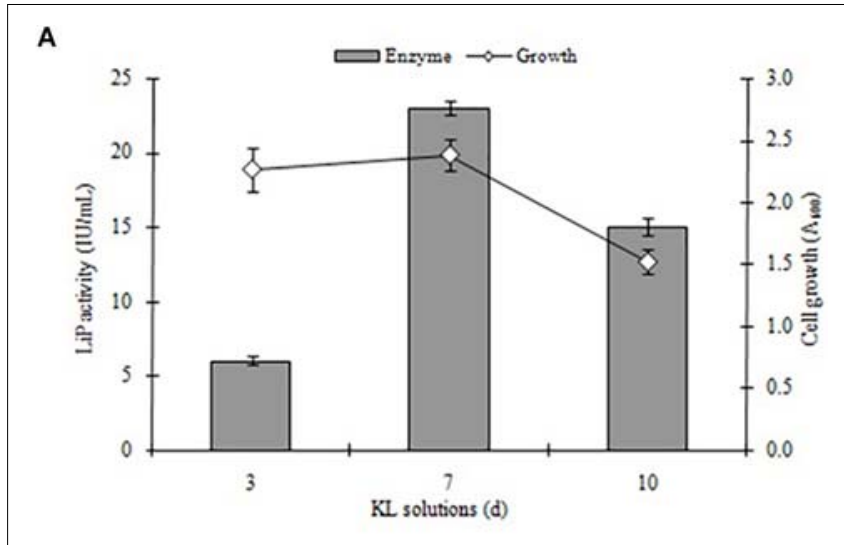

B

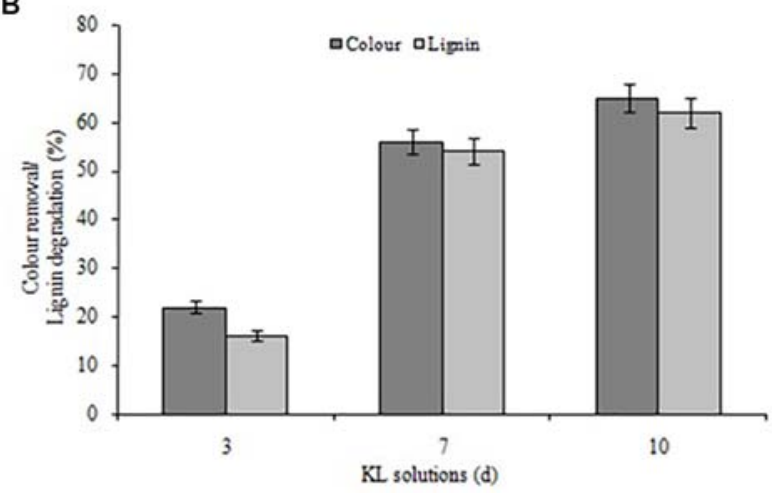

FIGURE 2 | (A) Bacterial growth and LiP activity and (B) KL degradation and decolorization induced by $S$. liquefaciens at different time points $(72,168$, and $240 \mathrm{~h}$, equivalent to 3,7 , and 10 days). The study was conducted at $30 \pm 1^{\circ} \mathrm{C}$ with shaking at $120 \mathrm{rpm}$. Values are mean $\pm S D(n=3)$.
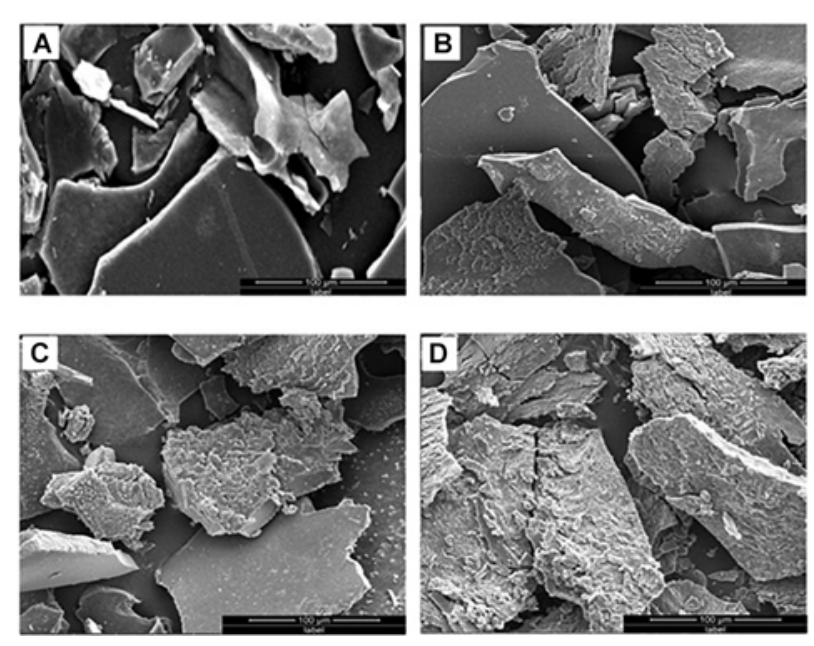

FIGURE 3 | SEM images of (A) untreated $\mathrm{KL}$ and bacterial-treated $\mathrm{KL}$ solution after (B) 72 , (C) 168, and (D) 240 h of incubation.

The control sample had absorption bands at around 3289 and $2932 \mathrm{~cm}^{-1}$. The band at $3289 \mathrm{~cm}^{-1}$ was replaced by bands at 3274,3275 , and $3269 \mathrm{~cm}^{-1}$ after 72,168 , and $240 \mathrm{~h}$ of bacterial
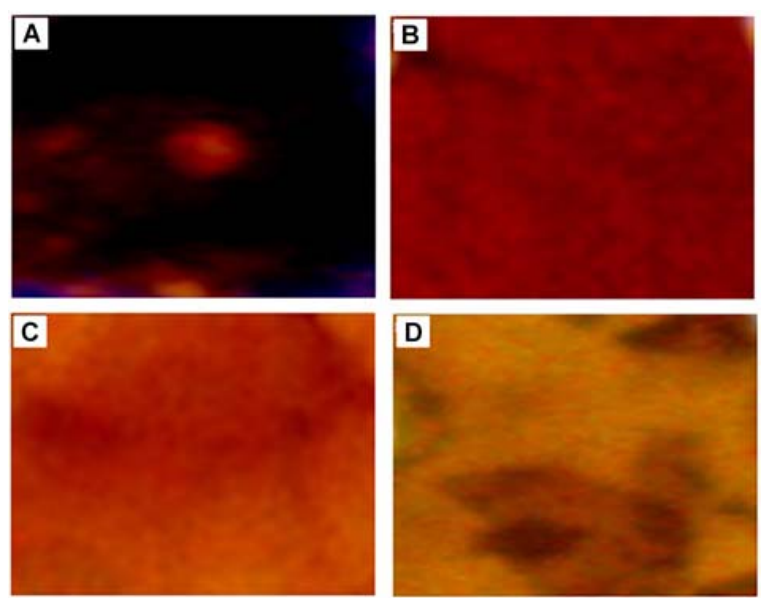

FIGURE 4 | Stereoscope microscopy images of (A) untreated $\mathrm{KL}$ and bacterial-treated KL solution after (B) 72, (C) 168, and (D) 240 h of incubation.

TABLE 1 | Mean particles size (hydrodynamic diameter, $D_{H}$ ) of control and bacterial-treated $\mathrm{KL}$ samples estimated by dynamic light scattering (DLS).

\begin{tabular}{lc}
\hline Sample & Peak (nm) \\
\hline UT & 334.8 \\
BT $(72$ h) & 300.4 \\
BT (168 h) & 292.8 \\
BT (240 h) & 275.1
\end{tabular}

UT, untreated; BT, bacteria-treated.

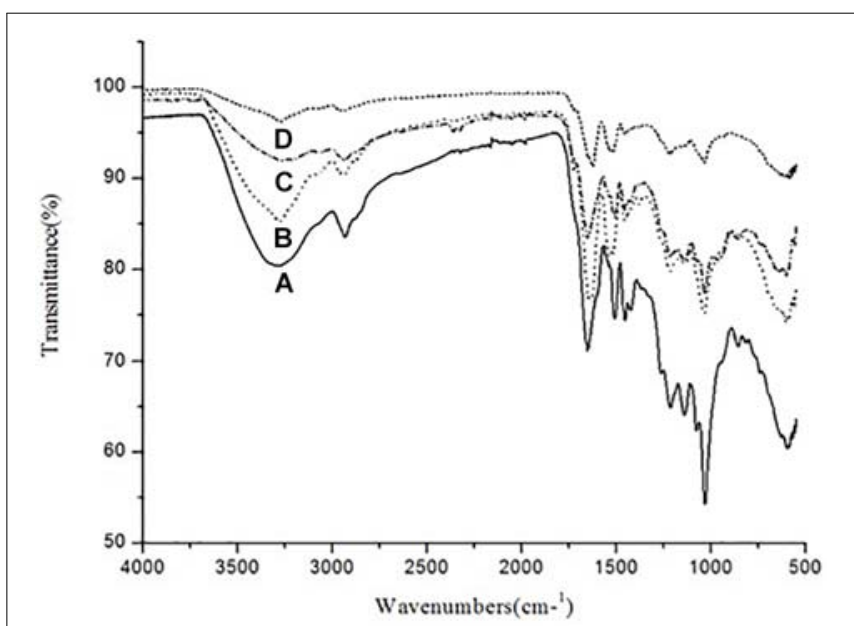

FIGURE 5 | ATR-FTIR spectra of (A) untreated $\mathrm{KL}$ and bacterial-treated $\mathrm{KL}$ solution after (B) 72, (C) 168, and (D) 240 h of incubation.

treatment, respectively. Similarly, the band at $2932 \mathrm{~cm}^{-1}$ was replaced by bands at 2934, 2935, and $2934 \mathrm{~cm}^{-1}$ after bacterial treatment, respectively. Thus, $\mathrm{O}-\mathrm{H}$, phenolic, aromatic, methyl, and methoxy groups were likely rearranged and transformed by S. liquefaciens to form new metabolites. The most prominent bands at around $1600 \mathrm{~cm}^{-1}$ assigned to aromatic skeletal vibrations were 1651, 1626, and $1627 \mathrm{~cm}^{-1}$ for $\mathrm{O}-\mathrm{H}$ and 
conjugated $\mathrm{C}-\mathrm{O}$ stretching. The peaks in the bacterial treated samples decreased in a time-dependent stepwise manner. These results were caused by changes in the number of carbonyl groups substituted at the para position of phenyl rings. The peaks at around $1500 \mathrm{~cm}^{-1}$ were attributable to $\mathrm{KL}$, as the bands arise purely due to aromatic skeletal vibration (C-C) in the KL. The peaks at around $1450 \mathrm{~cm}^{-1}$ were triggered by the extending of the KL phenol-ethers (Xu et al., 2013), while the $1210 \mathrm{~cm}^{-1}$ peak represents $\mathrm{C}-\mathrm{O}$ stretching and $\mathrm{C}-\mathrm{O}$ linkage in guaiacyl aromatic methoxyl groups, and the $1140 \mathrm{~cm}^{-1}$ peak represents syringyl ring and $\mathrm{C}-\mathrm{O}$ stretching in the KL (Pandey and Pitman, 2003). The bands at $1038 \mathrm{~cm}^{-1}$ were due to guaiacyl $(\mathrm{G})$ and syringyl (S) groups. The analysis of the ATR-FTIR spectra of the bacterialtreated KL samples evidenced the occurrence of delignification in a time-dependent manner.

\section{KL Characterization by GC-MS/MS Analysis}

The GC-MS assessment has further verified KL's bacterial biotransformation. The result has highlighted in Figures 6AD and Table 2. GC-MS of ethyl extracts of untreated KL solution (Figure 6A) has shown the presence of various organic compounds such as hexadecanoic acid
$(\mathrm{RT}=27.29), 1,5$-pentanediyl ester $(\mathrm{RT}=13.35)$, 2-allyl5-t-butylhydroquinone $(\mathrm{RT}=17.73), \quad$ dl-alanyl-l-leucine $(\mathrm{RT}=22.22), 1,4$-diaza-2,5-dioxobicyclo nonane $(\mathrm{RT}=22.66)$, 5-chlorobenzimidazole-2-carboxylic acid $(\mathrm{RT}=23.55)$, 2-non-enoic acid $(\mathrm{RT}=23.76), 5$-chlorobenzimidazole2-carboxylic acid (24.05), 1,4-diaza-2,5-dioxo-3-isobutyl bicycle nonane $(\mathrm{RT}=25.48), 2,5$-piperazinedione, 3,6-bis $(2$ methylpropyl) $(\mathrm{RT}=29.48)$, 3-benzyl-1,4-diaza-2,5-dioxobicyclo nonane $(\mathrm{RT}=31.88), 2$-acetylamino-3-phenylpropionic acid, 1 -carbamoylethyl ester $(\mathrm{RT}=34.65)$, and $N, N^{\prime}$-dicyclohexyl1-cyano-7-pyrrolidinylperylene-3,4:9,10-tetracarboxylic acid bisimide $(\mathrm{RT}=48.47)$. However, these compounds were not diminished in the ethyl acetate extract of the bacterial treated $\mathrm{KL}$ solution (Figures 6B-D).

Further, the analysis of the bacterial treated KL solutions indicated the presence of several new peaks at various time points (Figures 6B-D). At the end of the experiment $(240 \mathrm{~h})$, the new peaks detected as metabolites were: propanoic acid $(\mathrm{RT}=7.67), 2$-butenoic acid $(\mathrm{RT}=14.71)$, docosane $(\mathrm{RT}=17.35)$, $N$-tetracosanol-1 $(\mathrm{RT}=32.04)$, thiopheno $\left[\mathrm{b}, \mathrm{b}^{\prime}\right]$ dicamphore 1,1 dioxide $(\mathrm{RT}=32.22)$, and 1,8-diphenyl-3,4,10,11-tetrahydro $[1,4]$ dioxino[2,3-g:5,6-g' $]$ diisoquinolinemethyl $(\mathrm{RT}=43.72)$. New compounds such as 2-methyl-2,3-dihydro-1H-benz[g] indole $(\mathrm{RT}=12.54)$ were found at both 72 and $240 \mathrm{~h}$, while

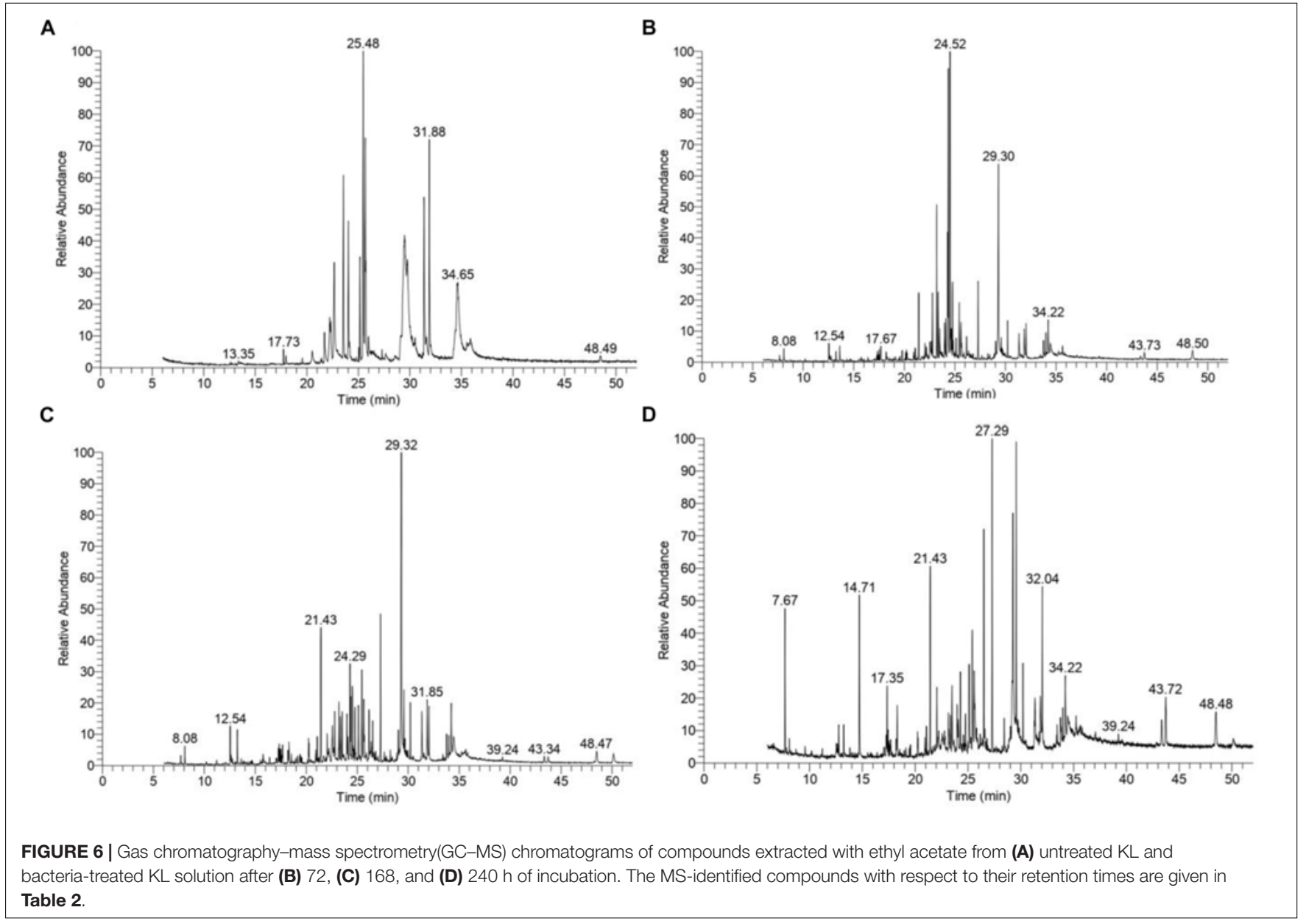


TABLE 2 | Compound identified as trimethylsilyl (TMS) derivatives in ethyl extract from untreated ( $<24 \mathrm{~h})$ and bacterial-treated $(72,168$, and $240 \mathrm{~h}) \mathrm{KL}$ samples as given in Figure 6.

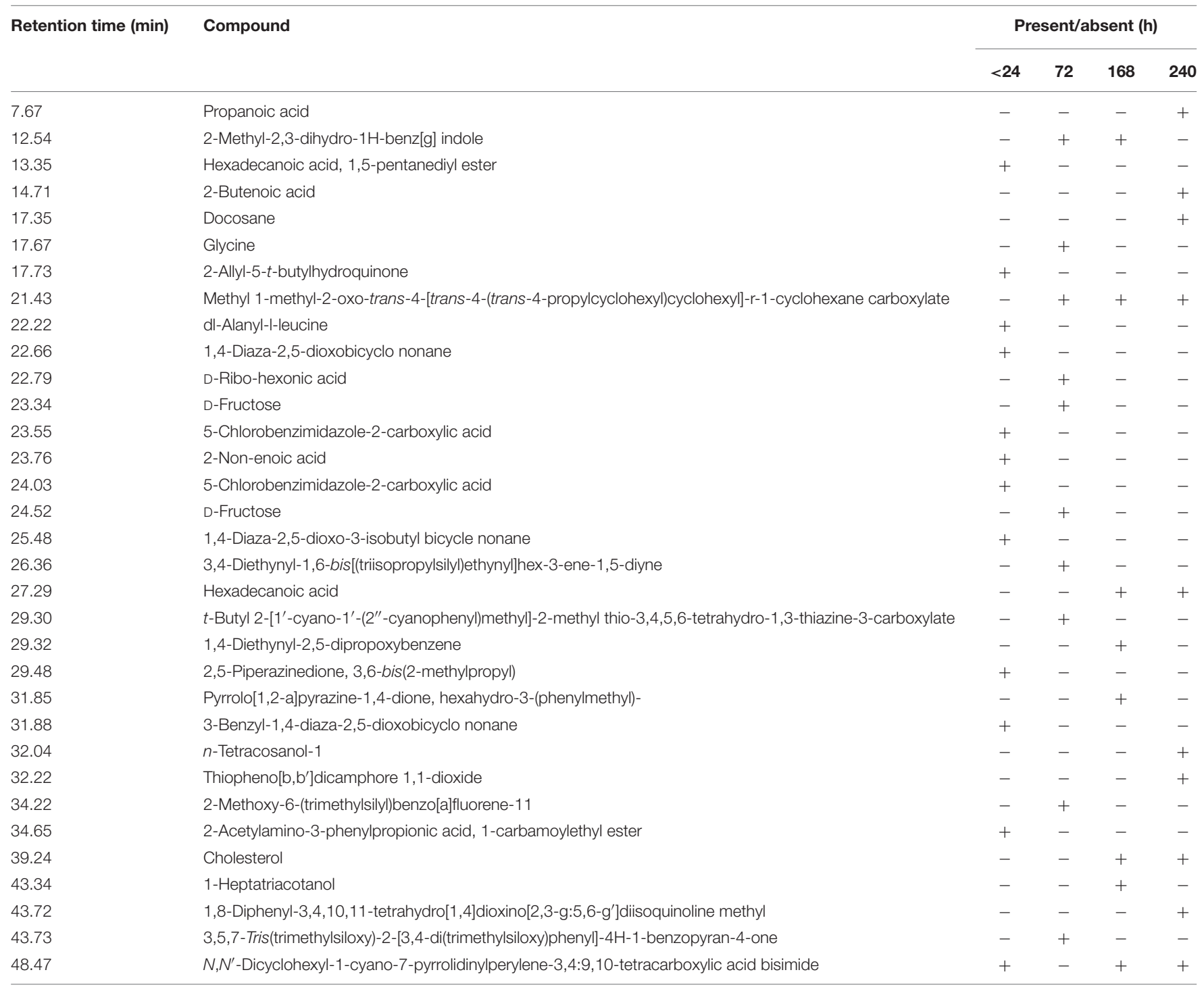

hexadecanoic acid $(\mathrm{RT}=27.29)$, cholesterol $(\mathrm{RT}=39.24)$, $N, N^{\prime}$-dicyclohexyl-1-cyano-7-pyrrolidinylperylene-3,4:9,10-

tetracarboxylic acid bisimide $(\mathrm{RT}=48.47)$ were found at both 168 and 240 h. Methyl 1-methyl-2-oxo-trans-4-[trans-4-(trans4-propylcyclohexyl) cyclohexyl]-r-1-cyclohexanecarboxylate $(\mathrm{RT}=21.43)$ was detected in all degraded samples. The results regarding the disappearance of compounds identified in the control sample and the formation of new peaks in the analysis of the degraded samples suggested that the bacterial strain has a strong ability to transform KL through metabolic activity. Most of the compounds detected were reported earlier during the bacterial degradation of KL and paper mill effluent (Raj et al., 2007; Abhishek et al., 2017).

\section{Cytotoxicity Evaluation of KL}

The cytotoxicity potential of the different KL solutions was determined using MTT and calcein-AM assays with a human kidney cell line (NRK-52E). In the MTT assay, after $24 \mathrm{~h}$ of exposure to the untreated $(<24 \mathrm{~h})$ and bacterial treated (72, 168, and $240 \mathrm{~h}) \mathrm{KL}$ solutions, the cell survival rate was 27, 47, 64, and 74\%, respectively. This indicated an increase in cell survival after bacterial treatment shown in Figure 7A. However, the MTT assay indicated that both untreated and bacterial treated KL solutions were cytotoxic to human kidney cells. Previous studies have reported on the cytotoxicity of paper mill effluents, based on MTT assays using various human cell lines (Abhishek et al., 2017). Further, the calcein-AM assay showed that, while the cell viability of the media control (MC) was unaffected by calcein-AM staining, a gradual increase in the cell viability was observed as the KL degradation increased shown in Figure 7B. Thus, after bacterial treatment of the KL solutions, cell proliferation and viability increased. The result suggested that the cytotoxicity of bacterial-treated $\mathrm{KL}$ solutions decreased significantly but not completely. All know 
A

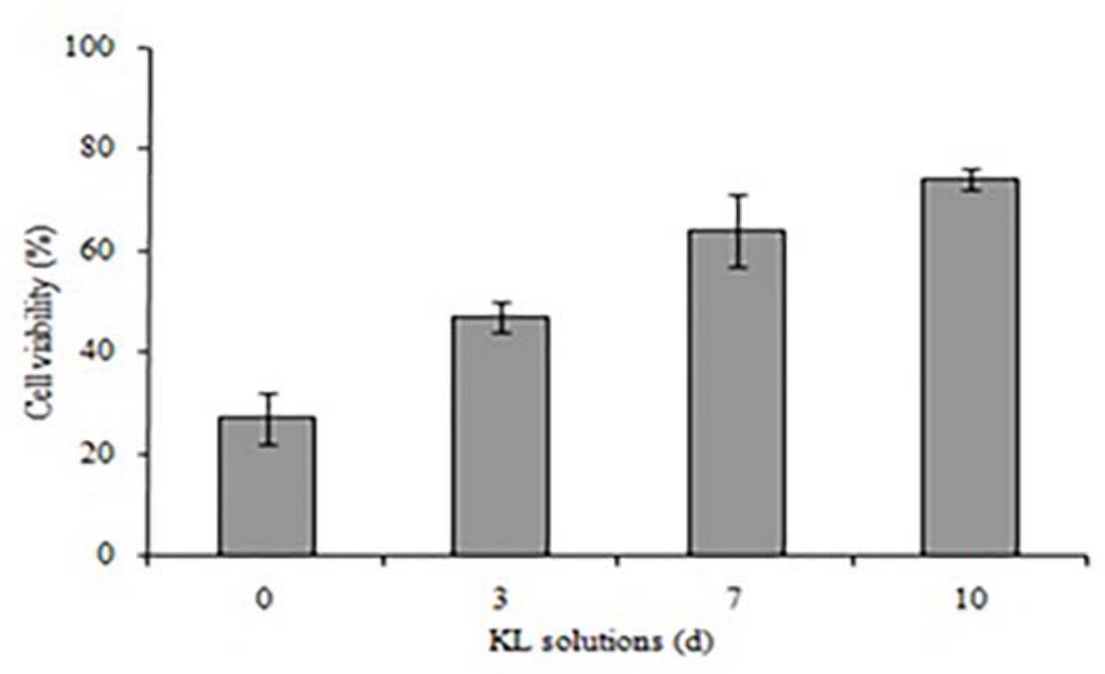

B

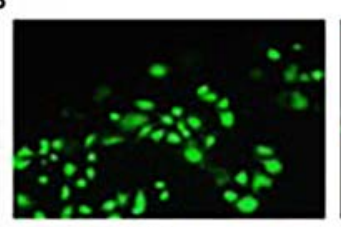

$\mathrm{MC}$

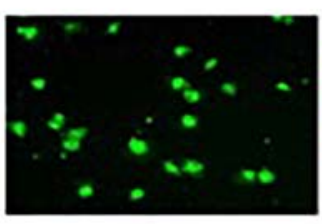

0

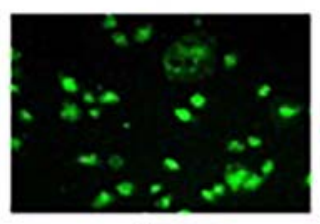

3

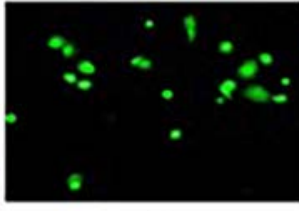

7

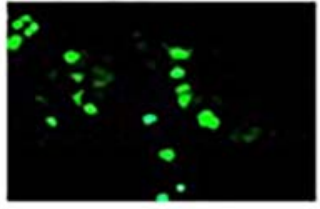

10

KL solutions (d)

FIGURE 7 | (A,B) Cytotoxicity of untreated (<24 h) and bacterial-treated (72, 168, and $240 \mathrm{~h}) \mathrm{KL}$ solution extracts using the NRK-52E cell line, as assessed by (A) MTT assay and (B) calcein-AM assay after exposure for $24 \mathrm{~h}$. MC, medium control. Values are mean $\pm S D(n=3)$.

it that there is no standard available for the lignin. Lignins are different types and their stricture is depending on the isolation source and methods. Hence, it is not possible to compare the results of the present work conducted with $\mathrm{KL}$ with those that were published previously. However, various studies reported cytotoxicity of lignins on various cell lines (Gordobil et al., 2019). Biodegradation along with detoxification reveals the potential of the bacterium to be used for lignin degradation (Barapatre et al., 2016).

\section{CONCLUSION}

Kraft lignin along with other lignins derivate compounds are the chief ingredients of paper mill effluents, which contribute to a dark appearance in color and pollution to water bodies. In the present study, we reported biodegradation/biotransformation $\mathrm{KL}$ by ligninolytic $S$. liquefaciens at very high concentration (1000 $\left.\mathrm{mg} \mathrm{L}^{-1}\right)$ with significant reduction of KL (65\%) and color (62\%). The KL biodegradation process of isolate was verified by instrumental analysis using SEM, DLS, ATR-FTIR, and GCMS. The KL was transformed into various less toxic metabolites. Further, bacterial treatment of KL led significant reduction in cytotoxicity. The above study can be concluded, S. liquefaciens could be an important tool to degrade KL by transforming it into various less toxic compounds as shown above by transforming and minimizing of cytotoxicity effects on kidney cell lines. Hence, concern bacteria may be useful to keep the environment free and safe from KL and lignin-derived pollutants.

\section{DATA AVAILABILITY STATEMENT}

The raw data supporting the conclusions of this manuscript will be made available by the authors, without undue reservation, to any qualified researcher.

\section{AUTHOR CONTRIBUTIONS}

AS was the first presenting author, and performed the lignin biodegradation, biotransformation assay, cytotoxicity assay, and GC-MS/MS extraction analysis. PY prepared the tables of manuscript and performed the sample preparation for GCMS/MS, ATR-FTIR, DLS, SEM, and EDX analyses. RB performed the statistical analysis and the interpretation of the results. GS performed and provided the input in statistical tests, figures, and overall manuscript editing with some corrections. AR provided the intellectual input, designed the study, and approved the protocols which have been followed in the study 
and finally carried out manuscript correction, proofread, and communicated the same.

\section{FUNDING}

This work was supported by the Department of Biotechnology (DBT) of the Government of India, and New Delhi (Grant No. BT/PR20460/BCE/8/1386/2016) to AR.

\section{REFERENCES}

Abhishek, A., Dwivedi, A., Tandan, N., and Kumar, U. (2017). Comparative bacterial degradation and detoxification of model and kraft lignin from pulp paper wastewater and its metabolites. Appl. Water Sci. 7, 757-767. doi: 10.1007/ s13201-015-0288-9

Ahmad, M., Taylor, C. R., Pink, D., Burton, K., Eastwood, D., Bending, G. D., et al. (2010). Development of novel assays for lignin degradation: comparative analysis of bacterial and fungal lignin degraders. Mol. Biosyst. 6, 815-821. doi: $10.1039 / \mathrm{b} 908966 \mathrm{~g}$

Barapatre, A., Meena, A. S., Mekala, S., Das, A., and Jha, H. (2016). In vitro evaluation of antioxidant and cytotoxic activities of lignin fractions extracted from Acacia nilotica. Int. J. Biol. Macromol. 86, 443-453. doi: 10.1016/j. ijbiomac.2016.01.109

Bugg, T. D., Ahmad, M., Hardiman, E. M., and Singh, R. (2011). The emerging role for bacteria in lignin degradation and bio-product formation. Curr. Opin. Biotechnol. 22, 394-400. doi: 10.1016/j.copbio.2010.10.009

Chandra, R., and Chowdhary, P. (2015). Properties of bacterial laccases and their application in bioremediation of industrial wastes. Environ. Sci. Process. Impacts 17, 326-342. doi: 10.1039/c4em00627e

Chandra, R., Raj, A., Purohit, H. J., and Kapley, A. (2007). Characterisation and optimisation of three potential aerobic bacterial strains for kraft lignin degradation from pulp paper waste. Chemosphere 67, 839-846. doi: 10.1016/ j.chemosphere.2006.10.011

Chen, Y. H., Chai, L. Y., Zhu, Y. H., Yang, Z. H., Zheng, Y., and Zhang, H. (2012). Biodegradation of kraft lignin by a bacterial strain Comamonas sp. B9 isolated from eroded bamboo slips. J. Appl. Microbiol. 112, 900-906. doi: 10.1111/j.1365-2672.2012.05275.x

Chowdhary, P., Shukla, G., Raj, G., Ferreira, L. F. R., and Bharagava, R. N. (2018). Microbial manganese peroxidase: a ligninolytic enzyme and its ample opportunities in research. SN Appl. Sci. 1:45. doi: 10.1007/s42452-018-0046-3

David Boyle, C. R., Kropp, B., and Reid, I. (1992). Solubilization and mineralization of lignin by white rot fungi. Appl. Environ. Microbiol. 58, 3217-3224.

Dwivedi, U. N., Singh, P., Pandey, V. P., and Kumar, A. (2011). Structure-function relationship among bacterial, fungal and plant laccases. J. Mol. Catal. B Enzym. 68, 117-128. doi: 10.1016/j.molcatb.2010.11.002

El Hanafy, A., Abd-Elsalam, H., and Hafez, E. (2008). Molecular characterization of two native egyptian ligninolytic bacterial strains. J. Appl. Sci. Res. 4, 1291-1296.

Fierro, V., Torné-Fernández, V., and Celzard, A. (2006). Kraft lignin as a precursor for microporous activated carbons prepared by impregnation with ortho-phosphoric acid: synthesis and textural characterisation. Microporous Mesoporous Mater. 92, 243-250. doi: 10.1016/j.micromeso.2006. 01.013

Gordobil, O., Oberemko, A., Saulis, G., Baublys, V., and Labidi, J. (2019). In vitro cytotoxicity studies of industrial Eucalyptus kraft lignins on mouse hepatoma, melanoma and Chinese hamster ovary cells. Int. J. Biol. Macromol. 135, 353-361. doi: 10.1016/j.ijbiomac.2019.05.111

Haq, I., Kumar, S., Kumari, V., Singh, S. K., and Raj, A. (2016). Evaluation of bioremediation potentiality of ligninolytic Serratia liquefaciens for detoxification of pulp and paper mill effluent. J. Hazard. Mater. 305, 190-199. doi: 10.1016/j.jhazmat.2015.11.046

Harms, H., Schlosser, D., and Wick, L. Y. (2011). Untapped potential: exploiting fungi in bioremediation of hazardous chemicals. Nat. Rev. Microbiol. 9, 177-192. doi: 10.1038/nrmicro2519

\section{ACKNOWLEDGMENTS}

$\mathrm{AR}$ is thankful to the Director of the CSIR-Indian Institute of Toxicology Research (IITR), Lucknow, India, for his encouragement and support. AR also acknowledges the Department of Biotechnology (DBT) of the Government of India, and New Delhi for financial support (grant no. BT/PR20460/BCE/8/1386/2016). This manuscript number 3607 (CSIR-IITR, manuscript communication record) also acknowledged.

He, P., and Aga, D. S. (2019). Comparison of GC-MS/MS and LC-MS/MS for the analysis of hormones and pesticides in surface waters: advantages and pitfalls. Anal. Methods 11, 1436-1448. doi: 10.1039/C8AY02774A

Ince, B., Cetecioglu, Z., and Ince, O. (2011). Pollution Prevention in the Pulp and Paper Industries. Rijeka: InTech.

Kamali, M., and Khodaparast, Z. (2015). Review on recent developments on pulp and paper mill wastewater treatment. Ecotoxicol. Environ. Saf. 114, 326-342. doi: 10.1016/j.ecoenv.2014.05.005

Kumar, M., Singh, J., Singh, M. K., Singhal, A., and Thakur, I. S. (2015). Investigating the degradation process of kraft lignin by beta-proteobacterium, Pandoraea sp. ISTKB. Environ. Sci. Pollut. Res. Int. 22, 15690-15702. doi: 10. 1007/s11356-015-4771-5

Latorre, A., Malmqvist, A., Lacorte, S., Welander, T., and Barceló, D. (2007). Evaluation of the treatment efficiencies of paper mill whitewaters in terms of organic composition and toxicity. Environ. Pollut. 147, 648-655. doi: 10.1016/j. envpol.2006.09.015

Lu, Y., Lu, Y.-C., Hu, H.-Q., Xie, F.-J., Wei, X.-Y., and Fan, X. (2017). Structural characterization of lignin and its degradation products with spectroscopic methods. J. Spectrosc. 2017:8951658. doi: 10.1155/2017/8951658

Mehboob, N., Asad, M. J., Imran, M., Gulfraz, M., Wattoo, F. H., Hadri, S. H., et al. (2011). Production of lignin peroxidase by Ganoderma leucidum using solid state fermentation. Afr. J. Biotechnol. 10, 9880-9887. doi: 10.5897/ajb11.768

Nath, S. (2016). Effect of paper mill effluents on morphological and hematological indices of Amblyceps mangois. J. Fish. Aquat. Sci. 11, 225-231. doi: 10.3923/jfas. 2016.225.231

Pandey, K. K., and Pitman, A. J. (2003). FTIR studies of the changes in wood chemistry following decay by brown-rot and white-rot fungi. Int. Biodeterior. Biodegradation 52, 151-160. doi: 10.1016/S0964-8305(03)00052-0

Pearl, I., and Benson, H. J. P. T. J. (1940). The determination of lignin in sulphide pulping liquor. Pap. Trad. J. 111, 35-36.

Pua, F.-l., Fang, Z., Zakaria, S., Guo, F., and Chia, C.-h. (2011). Direct production of biodiesel from high-acid value Jatropha oil with solid acid catalyst derived from lignin. Biotechnol. Biofuels 4:56. doi: 10.1186/1754-6834-4-56

Raj, A., Kumar, S., Haq, I., and Singh, S. K. (2014). Bioremediation and toxicity reduction in pulp and paper mill effluent by newly isolated ligninolytic Paenibacillus sp. Ecol. Eng. 71, 355-362. doi: 10.1016/j.ecoleng.2014.07.002

Raj, A., Reddy, M. M., Chandra, R., Purohit, H. J., and Kapley, A. (2007). Biodegradation of kraft-lignin by Bacillus sp. isolated from sludge of pulp and paper mill. Biodegradation 18, 783-792. doi: 10.1007/s10532-007-9107-9

Ravi, K., Abdelaziz, O. Y., Nöbel, M., García-Hidalgo, J., Gorwa-Grauslund, M. F., Hulteberg, C. P., et al. (2019). Bacterial conversion of depolymerized kraft lignin. Biotechnol. Biof. 12:56. doi: 10.1186/s13068-019-1397-8

Remedios, M., Carvalho, F. A., Enguita, F. J., Cardoso, C., Martins, I. C., Santos, N. C., et al. (2016). Effects of Penicillium chrysogenum var. halophenolicum on kraft lignin: color stabilization and cytotoxicity evaluation. 3 Biotech 6:102. doi: 10.1007/s13205-016-0414-x

Rybczyńska-Tkaczyk, K., and Korniłłowicz-Kowalska, T. (2017). Biotransformation and ecotoxicity evaluation of alkali lignin in optimized cultures of microscopic fungi. Int. Biodeterior. Biodegradation 117, 131-140. doi: 10.1016/j.ibiod.2016.12.011

Sainsbury, P. D., Hardiman, E. M., Ahmad, M., Otani, H., Seghezzi, N., Eltis, L. D., et al. (2013). Breaking down lignin to high-value chemicals: the conversion of lignocellulose to vanillin in a gene deletion mutant of Rhodococcus jostii RHA1. ACS Chem. Biol. 8, 2151-2156. doi: 10.1021/cb400505a 
Saratale, R., Saratale, G., Chang, J.-S., and Govindwar, S. (2009). Decolorization and biodegradation of textile dye navy blue HER by Trichosporon beigelii NCIM3326. J. Hazard. Mater. 166, 1421-1428. doi: 10.1016/j.jhazmat.2008.12.068

Sharma, P., Goel, R., and Capalash, N. (2007). Bacterial laccases. World J. Microbiol. Biotechnol. 23, 823-832. doi: 10.1007/s11274-006-9305-3

Shi, Y., Chai, L., Tang, C., Yang, Z., Zheng, Y., Chen, Y., et al. (2013). Biochemical investigation of kraft lignin degradation by Pandoraea sp. B-6 isolated from bamboo slips. Bioprocess. Biosyst. Eng. 36, 1957-1965. doi: 10.1007/s00449-0130972-9

Singh, P. (2012). Removal of color, COD and lignin from pulp and paper mill effluent by Phanerochaete chrysosporium and Aspergillus fumigates. J. Chem. Pharm. Res. 4, 4522-4532.

Singh, R. D., Tiwari, R., Khan, H., Kumar, A., and Srivastava, V. (2015). Arsenic exposure causes epigenetic dysregulation of IL-8 expression leading to proneoplastic changes in kidney cells. Toxicol. Lett. 237, 1-10. doi: 10.1016/j. toxlet.2015.05.014

Sponza, D. T. (2003). Application of toxicity tests into discharges of the pulp-paper industry in Turkey. Ecotoxicol. Environ. Saf. 54, 74-86. doi: 10.1016/s01476513(02)00024-6

Suresh, S., and Hung, Y.-T. (2004). Treatment of Pulp and Paper Mill Wastes. Rijeka: InTech, 469-513.

Swift, M. L. (1997). GraphPad prism, data analysis, and scientific graphing. J. Chem. Inform. Comput. Sci. 37, 411-412. doi: 10.1021/ci960402j

Tian, J. H., Pourcher, A. M., and Peu, P. (2016). Isolation of bacterial strains able to metabolize lignin and lignin-related compounds. Lett. Appl. Microbiol. 63, 30-37. doi: 10.1111/lam.12581
Tien, M., and Kirk, T. K. (1988). "Lignin peroxidase of Phanerochaete chrysosporium," in Methods in Enzymology, Vol. 161, ed. J. Abelson (Cambridge, CA: Academic Press), 238-249. doi: 10.1016/0076-6879(88)61025-1

Verma, M., and Ekka, A. (2018). Decolorization and degradation of kraft lignin discharged from pulp and paper mill industry by axenic and co-culture of Bacillus sp. Res. J. Pharm. Technol. 11, 4386-4892. doi: 10.5958/0974-360X. 2018.00802.8

Wang, D., Lin, Y., Du, W., Liang, J., and Ning, Y. (2013). Optimization and characterization of lignosulfonate biodegradation process by a bacterial strain, Sphingobacterium sp. HY-H. Int. Biodeterior. Biodegradation 85, 365-371. doi: 10.1016/j.ibiod.2013.06.032

Xu, G., Wang, L., Liu, J., and Wu, J. (2013). FTIR and XPS analysis of the changes in bamboo chemical structure decayed by white-rot and brown-rot fungi. Appl. Surf. Sci. 280, 799-805. doi: 10.1016/j.apsusc.2013. 05.065

Conflict of Interest: The authors declare that the research was conducted in the absence of any commercial or financial relationships that could be construed as a potential conflict of interest.

Copyright $\odot 2019$ Singh, Yadav, Bharagava, Saratale and Raj. This is an open-access article distributed under the terms of the Creative Commons Attribution License (CC BY). The use, distribution or reproduction in other forums is permitted, provided the original author(s) and the copyright owner(s) are credited and that the original publication in this journal is cited, in accordance with accepted academic practice. No use, distribution or reproduction is permitted which does not comply with these terms. 